Examination.-The head appeared to be of normal dimensions; the occiput presented in L. O. I. A. position, and was anengaged at the brim. The surroundings were very unhygitnic and no measurements were taken, though the anteroposterior diameter seemed shortened.

De'ivery.-Simpson long forceps were applied and delivery was $\mathrm{t}$ ffected in an hour without undue force in the extraction. A feeling of crepitation was experienced while the head was descending, but it made no special impression at the time. The fetus was normal in appearance but was stillborn; its weight was eight pounds. There was a small perineal tear which was repaired. After a thorough examination there was discovered a separation at the symphysis about $1.5 \mathrm{~cm}$. wide. The urethra was torn and displaced to the right with consequent partial incontinence of urine. There was a fracture of the right ascending ramus of the ischium about $3 \mathrm{~cm}$. below the symphysis. The measurement between the anterior-superior spines of the ilium was $25 \mathrm{~cm}$. in the relaxed condition.

Subsequent History.-The hips were bandaged. The patient had a septic temperature for a month and finally an abscess developed between the layers of the abdominal muscles on the left side, just above Poupart's ligament. It was opened and drained, but a sinus persisted. The factured bone united promptly, but about the end of the second month septic pneumonia developed and the woman died Dec. 29, 1908, three months after delivery.

The pubic separation remained, notwithstanding the efforts at bandaging. The fracture was evidently produced by the passage of the head through the outlet, showing that even after a symphyseotomy the possibility of a fracture should be borne in mind in cases of contracted pelvis.

\section{A DEVICE FOR MEASURING FLEXION DE- FORMITY IN HIP-JOINT DISEASE}

\section{JOHN JOSEPH NUTT, M.D. NEW YORK}

As the increase or decrease of deformity in this disease is a most helpful guide to the efficiency of treatment, an accurate and easy method of measurement is demanded. It is probably true that months of treatment might often be avoided by the early recognition of an increasing deformity. Failure to appreciate the value of studying the slight variations in the signs of

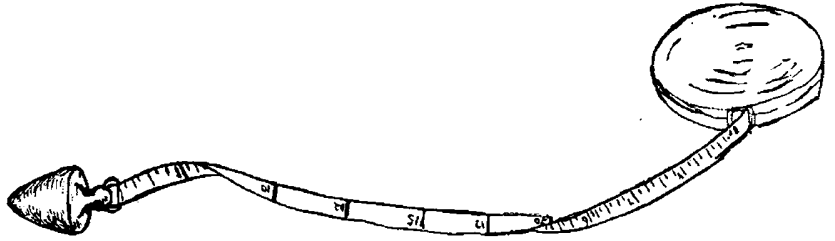

a joint disease has been responsible, probably, for the retention of such gross mechanical treatment as the gypsum cast, with an unwarranted faith that air and eggs will accomplish the rest.

We already have a sufficiently accurate method in the one worked out by Kingsley, ${ }^{1}$ but as it necessitates the use of a reference table it is difficult of application.

'The device herewith presented transfers this table from the printed page to one side of a tape measure. Instead of reading one side of a triangle in inches and then referring to the table for the degrees of the angle opposite, the degrees of the angle can be read directly from the tape.

Kingsley's table consists of the computations of the angles subtended by a series of perpendiculars in right-

1. Boston Med. and Surg. Jour., July 5,1888 . angled triangles, the hypothenuse of which is constant. With the patient on the examining table, the leg on the diseased side is held in its position of greatest extension, as indicated by the fumbar spine. A hypothenuse of twenty-four inches is measured from the table, opposite the joint, in the line of the limb, and from its end a perpendicular is dropped to the table and measured. By referring to Kingsley's tabulation the angle at the hip may be found.

Attaching a plumb-bob to a tape line, I measured inches from the tip of the bob and marked each with the angle which such a perpendicular would subtend in a right-angled triangle with a hypothenuse of twentyfour inches. In using this tape some one holds the leg in the deformed position. Twenty-four inches are measured along the leg and the plumb-tape dropped to the table. The angle of flexion is read directly from the tape.

\section{THE USE OF ATROPIN SULPHATE IN ANES- THETIZING BIRDS FOR SURGICAL EXPERIMENTS *}

RAymond Pearl, Ph.D. and FRANK M. SURfaCE, Ph.D Biologist and Associate Biologist, Maine Agricultural Experiment Station ORONO, MAINE

In 1907 an investigation was begun in this laboratory on the physiology of reproduction in the domestic fowl. It was the plan of this investigation to use in the main experimental surgical methods in the analysis of the problems involved. Such experiments were begun in the fall of $190 \%$. Much of the detailed technic involved in these experiments had to be worked out ad hoc, both with reference to the character of the problems studied and to the nature of the material itself.

At the beginning of our operative work on birds a great deal of difficulty was experienced in the matter of anesthesia. Such a difficulty had not been foreseen and for a time greatly hindered the progress of the work. It is difficult for one who has been accustomed to the behavior of mammals under anesthesia to realize how differently birds behave under similar treatment. At the outstart of the work chloroform was used as an anesthetic. After a number of birds had been killed on the table by the action of the chloroform it seemed clear that some change in the technic must be made. Resort was next had to ether. Better results were obtained, but still a great deal of difficulty was experienced.

The difficulty which we have found to be inherent in anesthetizing the domestic fowl may be stated briefly in this way: If any anesthetic is pushed to the point at which the bird is in satisfactory condition for operative procedure, in about nine cases out of ten the bird will die on the table from the effects of the anesthesia before the operation, if extensive, can be completed. If, on the other hand, the anesthetic is given less freely the bird does not lose its reflex excitability. Every time a cut is made or a nerve is pinched with the forceps the bird will struggle. Our experience in anesthetizing birds, which has now covered a large number of individuals, leads us to believe that the only middle ground between these two extremes is afforded by those cases (unfortunately too few) in which the imdividual idio-

* From the Biological Laboratory of the Maine Agricultural Experiment Station. 
syncrasy of the bird toward ether make it take the anesthetic well.

While we have made no detailed physiologic study as to the fundamental reasons underlying this difficulty respecting anesthesia which has been described, it seems reasonably apparent what these reasons are. Connected with the respiratory organs proper of a bird are the relatively enormous air sacs. During anestbesia the ether or chloroform vapor gets into these air sacs either by diffusion. or directly as a result of respiratory movements. There is reason to believe that the vapor, once in the air sacs, stays there until it is absorbed by the tissues; in other words, it appears to be the case that the great bulk of an inhaled anesthetic in the case of birds must be eliminated from the body by way of the urinary organs rather than the respiratory organs. Assuming this to be the case there is no difficulty in scein $\mathrm{s}$ wh forcing an anesthetic in a bird leads to disastrous results. The relatively enormous area for $a b-$ sorption afforded by the air sacs insures that a correspondingly large amount of the anesthetic will be taken up very quickly. This almost immediately affects the vagus center, with the consequent cardiac inhibition, respiratory failure and death.

In attempting to overome this difficulty a considerable number of experiments were tried with indifferent success. Nearly every method of anesthesia which has be $n$ advocated was tried. From the glowing reports in the literature we were led to hope that scopolamin-morphin might prove to be the desired thing. A series of experiments with these drugs, in which various doses ranging from very small to very large were thoroughly tested, failed to yield satisfactory results. We found it jmpossible to induce satisfactory surgical anesthesia in fowls by injecting scopolamin-morphin. After various failures we finally began the routine use of atropin sulphate in connection with the anesthetic. Our idea was that if at the same time that the anesthetic was given to the bird some substance could also be given which should have the effect of neutralizing partially or completely the poisonous action of the anesthetic without destroying its anesthetizing effect it would then be possible to give the bird sufficiently large doses to attain the desired surgical condition without killing it. Now it is a well-known fact that atropin is antagonistic in its pharmacologic act on to substances like chloroform and ether. The suggestion was at once obvious that if atropin were not antagonistic to these other drugs in respect to anesthetic action, the poisoning might be obriated without disturbing the anesthesia by injecting into the organism, when the anesthesia was begun, a certain amount of atropin. The use of this drug in connection with chloroform or ether anesthesia has been advocated, ${ }^{2}$ but, so far as we can learn, only to a very slight extent practiced.

This scheme of anesthesia was carried into effect in our work with birds in January, 1908. It may be said at once that the results from its use have been successful beyond anticipation. In our work we have kept birds on the operating table under the influence of the anesthetic for three or four eonsecutive hours, and at the same time carried on extensive surgical manipula-

1. Cushny, A. R.: Text-Book of Pharmacology, pp. 285-289.

2. Cushny : Text-Book of Pharmacology, p. 175. Schäfer, it. A. : Artificial Respiration in its Physiologic Aspects, THE JourNá A. M. A., Sept. 5, 1908, li, 801, Schäfer says: (loc. cit., p. $803)$ : "Both these dangers are obviated by the hypodermic admin-
istration, prior to the operation, of a small dose $(1 / 50$ grain) of atropin sulphate. It seems strange that anesthetists do not generally adopt this simple precaution as a routine method." tions without the least ill effect from the prolonged inhalation of the anesthetic. Not only do the birds which have been given atropin in connection with the anesthetic survive prolonged and deep anesthesia, but they are in much better condition for the operation than those not so treated. Relaxation is complete and reflex activity disappears. A preliminary injection of scopolamin-morphin (morphin sulphate $1 / 3 \mathrm{gr}$., scopolaminhydrobromide $1 / 75 \mathrm{gr}$.) we have tried in the place of atropin sulphate. The resulting anesthesia with ether is better than. when the ether is used alone, but in our experience it is not so satisfactory as when the atropin is used.

The exact method of procedure which we now follow in anesthetizing birds is as follows: Immediately before beginning the administration of the anesthetic a $1 / 200$ grain atropin sulphate tablet is dissolved in 1 c.c. of warm normal saline solution. The salt solution with the dissolved atropin is then injected subcutareously in the axilla. Ether is used as the anesthetic. It is administered from a small improvised mask which admits of the condition of the comb being seen during the operation. Depending on how hard the ether is pushed, the bird is ready for operation in from fifteen to twenty minutes after the anesthesia is begun. The dosage of 1/200 grain atropin to a bird may seem large, but we have never been able to see the slightest bad effect from it, provided the administration of ether was begun immediately after the injection of the atropin.

\section{DIAGNOSIS AND TREATMENT OF CATAR- RHAL PNEUMONIA COMPLICATING IN- FECTIOUS DISEASES OF CHILDHOOD}

\section{ARTHUR STERN, M.D. ELIZABETH, N. J.}

The statistics of the various boards of health in the large cities of the United States show clearly the danger of the pulmonary complications of infectious diseases in childhood. In New York City, during the week ended Jan. 4, 1908, 581 cases of measles were reported to the health departmen', with 32 deaths, and if it is remembered that the majority of these deaths were due not to the disease per se but to the lung complications, it will be seen that these constitute an important factor in the management of the case.

The danger is in direct proportion to the size of the bronchi affected. When only the large bronchi are involved the danger is comparatively small, but as soon as the inflammation extends to the bronchioles, with exudation into the alveoli, the situation becomes serious.

The physical diagnosis of these conditions is not easy. The bronchopneumonia following bronchitis can be diagnosed only if the amount of healthy lung tissue is not large enough to mask the infiltration; in other words, if there are many infiltrated spots spread over the lungs, symptoms of bronchitis may be made out by auscultation, and the extremely rapid respiration will tell more than the ear.

The danger and prognosis in these cases may be just as grave as in cases in which there is perceptible flatness on percussion. Therefore, I always base my prognosis or: the pulse, respiration and general facial expression rather than on the percussion and auscultation of the child's thorax. Sometimes, no matter how careful I have been in examining a child, I could hear nothing but signs of a general catarrhal condition of the larger 